\title{
Coupling between the JULES land-surface scheme and the CCATT-BRAMS atmospheric chemistry model (JULES-CCATT-BRAMS1.0): applications to numerical weather forecasting and the $\mathrm{CO}_{2}$ budget in South America
}

\author{
D. S. Moreira ${ }^{1}$, S. R. Freitas ${ }^{1}$, J. P. Bonatti ${ }^{1}$, L. M. Mercado ${ }^{2,3}$, N. M. É. Rosário ${ }^{4}$, K. M. Longo ${ }^{5}$, J. B. Miller ${ }^{6,7}$, \\ M. Gloor ${ }^{8}$, and L. V. Gatti ${ }^{9}$ \\ ${ }^{1}$ Center for Weather Forecasting and Climate Studies, INPE, Cachoeira Paulista, SP, Brazil \\ ${ }^{2}$ University of Exeter, College of Life and Environmental Sciences, Exeter, EX4 4RJ, UK \\ ${ }^{3}$ Centre for Ecology and Hydrology, Wallingford, Oxon OX10 8BB, UK \\ ${ }^{4}$ UNIFESP - Evironmental Sciences Division, Rua Prof. Artur Riedel, 275, Diadema, SP, Brazil \\ ${ }^{5}$ Earth System Science Center, INPE, São José dos Campos, SP, Brazil \\ ${ }^{6}$ NOAA/ESRL R/GMD1 325 Broadway, Boulder, CO 80305, USA \\ ${ }^{7}$ CIRES, University of Colorado, Boulder, CO 80309, USA \\ ${ }^{8}$ University of Leeds, School of Geography, Woodhouse Lane, Leeds, LS2 9JT, UK \\ ${ }^{9}$ CNEN - IPEN - Lab. Quimica Atmosferica, Av. Prof. Lineu Prestes, 2242, Cidade Universitaria, São Paulo, SP, Brazil
}

Correspondence to: D. S. Moreira (demerval.moreira@cptec.inpe.br)

Received: 10 December 2012 - Published in Geosci. Model Dev. Discuss.: 23 January 2013

Revised: 2 July 2013 - Accepted: 3 July 2013 - Published: 22 August 2013

\begin{abstract}
This article presents the coupling of the JULES surface model to the CCATT-BRAMS atmospheric chemistry model. This new numerical system is denominated JULES-CCATT-BRAMS. We demonstrate the performance of this new model system in relation to several meteorological variables and the $\mathrm{CO}_{2}$ mixing ratio over a large part of South America, focusing on the Amazon basin. The evaluation was conducted for two time periods, the wet (March) and dry (September) seasons of 2010. The model errors were calculated in relation to meteorological observations at conventional stations in airports and automatic stations. In addition, $\mathrm{CO}_{2}$ mixing ratios in the first model level were compared with meteorological tower measurements and vertical $\mathrm{CO}_{2}$ profiles were compared with observations obtained with airborne instruments. The results of this study show that the JULES-CCATT-BRAMS modeling system provided a significant gain in performance for the considered atmospheric fields relative to those simulated by the LEAF (version 3) surface model originally employed by CCATT-BRAMS. In addition, the new system significantly increases the ability to simulate processes involving air-surface interactions, due
\end{abstract}

to the ability of JULES to simulate photosynthesis, respiration and dynamic vegetation, among other processes. We also discuss a wide range of numerical studies involving coupled atmospheric, land surface and chemistry processes that could be done with the system introduced here. Thus, this work presents to the scientific community a free modeling tool, with good performance in comparison with observational data and reanalysis model data, at least for the region and time period discussed here. Therefore, in principle, this model is able to produce atmospheric hindcast/forecast simulations at different spatial resolutions for any time period and any region of the globe.

\section{Introduction}

Before the beginning of the industrial era, around the year 1750 , the atmospheric carbon dioxide $\left(\mathrm{CO}_{2}\right)$ concentration was roughly $280 \mathrm{ppm}$, but has continually increased since then (Keeling, 1997). The growth of atmospheric $\mathrm{CO}_{2}$ is mostly caused by anthropogenic emissions, principally from 
fossil fuel and biomass burning. The main sinks of atmospheric $\mathrm{CO}_{2}$ are the oceans and forests. The terrestrial biosphere continually sequesters 20 to $30 \%$ of anthropogenic $\mathrm{CO}_{2}$ emissions, and studies suggest that Amazonia has been one of the largest contributors to atmospheric $\mathrm{CO}_{2}$ removal (Baker et al., 2004). Accurate understanding and representation of the Amazon forest $\mathrm{CO}_{2}$ exchange processes and their interaction with the atmosphere in climate models is critical to a consistent modeling of the regional and global $\mathrm{CO}_{2}$ budget. In South America, during the biomass burning season, fires represent the largest source of atmospheric $\mathrm{CO}_{2}$; however, various other gases are also emitted, which contribute to the greenhouse effect either directly or indirectly through the formation of secondary gases, such as ozone. Previous studies suggested that the assimilation of ozone is likely to significantly affect forest net productivity (Sitch et al., 2007). In addition to gases, vegetation fires also produce particulate material (Andreae, 1991; Artaxo et al., 2002; Andreae et al., 2004), which has a significant impact on the radiation budget, cloud microphysics and the hydrologic cycle (Kaufman, 1995; Rosenfeld, 1999; Andreae et al., 2004; Koren et al., 2004), and thus affects surface processes by altering the availability of energy and precipitation. It has been suggested that the interaction between biomass burning aerosols and solar radiation alters the photosynthesis process in the Amazon rainforest through the attenuation of the amount of solar radiation arriving at the surface and via the increase of the diffuse fraction (Yamasoe et al., 2006). The potential impact of all these processes can be considerable since, during the peak of the fire season, smoke plumes can cover areas of millions of $\mathrm{km}^{2}$ (Prins et al., 1998).

To fill in the gaps in observed data, to conduct fictitious experiments (for example, changing the vegetation type in a given region), and to predict the weather, the scientific community has widely used numerical modeling. From the knowledge of the processes that occur in nature, physical equations are developed to simulate these processes as realistically as possible. However, due to the complexity and interaction of all processes occurring in the atmosphere and at the surface, it can be said that we will never be able to reproduce and/or predict exactly all phenomena that govern nature. However, with observations of nature, it is possible to develop equations more appropriate to a particular event, and with the advancement of computing, more complex equations can be implemented in numerical models and the approaches used to accelerate the calculations can be reduced. Therefore, models are increasingly able to approximate reality. Thus, this work has as its main goal the inclusion of the JULES surface scheme, a model that comprises several new processes and is widely used and under continuous development, as an alternative to the LEAF scheme.

CCATT-BRAMS (Coupled Chemistry-Aerosol-Tracer Transport model to the Brazilian developments on the Regional Atmospheric Modeling System) (Freitas et al., 2009; Longo et al., 2013) is a numerical system developed at the Brazilian National Institute for Space Research (INPE) aimed at regional-scale weather forecasting and atmosphere chemistry and air quality research. Currently, the CCATT-BRAMS surface scheme is based on the LEAF (Walko et al., 2000) model for prediction of temperature, soil water content, snow cover and vegetation temperature, and includes exchange of turbulent and radiative fluxes between these components and the atmosphere. However, LEAF does not include air-surface exchanges of $\mathrm{CO}_{2}$ (photosynthesis and respiration), other trace gases, or a dynamic vegetation formulation, among other processes. In this study, the Joint UK Land Environment Simulator (JULES) surfaceatmosphere interaction model (Best et al., 2011; Clark et al., 2011) was coupled to the CCATT-BRAMS model. JULES is considered state of the art in terms of the representation of surface processes, with modern formulations able to simulate the large number of processes that occur at the surface, including vegetation dynamics, carbon storage, soil moisture, photosynthesis and plant respiration. Thus, an integrated model (JULES-CCATT-BRAMS) was created, capable of simulating most of the principal processes that occur at the surface and in the terrestrial atmosphere, and their interactions.

This paper is organized as follows. Section 2 provides a brief description of the numerical models that are coupled. It describes the BRAMS atmospheric model; the CCATT model, which is responsible for the transport of gases and aerosols; and the JULES model, responsible for predicting the processes that occur at the surface. At the end of this section the coupled model (JULES-CCATT-BRAMS) is described, and the initial and boundary conditions necessary for execution of the model are presented. Section 3 shows the evaluation and sensitivity of JULES-CCATT-BRAMS to various configurations in wet and dry seasons. Finally, Section 4 gives a brief summary of the article.

\section{System components and coupling of JULES to CCATT-BRAMS}

\subsection{The BRAMS atmospheric component}

The Brazilian developments on the Regional Atmospheric Modeling System is based on the Regional Atmospheric Modeling System (RAMS, Walko et al., 2000), with several modifications to improve the numerical representation of key physical processes over tropical and subtropical regions.

According to Freitas et al. (2009), RAMS is a numerical model designed to simulate atmospheric circulations at many scales. RAMS solves the fully compressible nonhydrostatic equations described by Tripoli and Cotton (1982) and is equipped with a multiple-grid nesting scheme which allows the model equations to be solved simultaneously on any number of two-way interacting computational meshes of increasing spatial resolution. It has a set of physical 
parameterizations appropriate for simulating processes such as surface-air exchanges, turbulence, convection, radiation and cloud microphysics.

Subdivision of a RAMS surface grid cell into multiple areas with distinct land-use types is allowed, with each subgrid area, or patch, containing its own surface model (LEAF), and each patch interacting with the overlying atmospheric column with a weight proportional to its fractional area in the grid cell.

As previously stated, BRAMS is based on the RAMS model, with new developments focusing on better representation of atmospheric processes in tropical regions. Features include a set of additional modern physical parameterizations and improved software quality (see Freitas et al., 2009, for more details).

\subsection{The CCATT atmospheric chemistry component}

CCATT is an Eulerian transport model coupled online with BRAMS and developed to simulate the transport, dispersion, chemical transformation and removal processes associated with gases and aerosols (Freitas et al., 2009; Longo et al., 2013). CCATT simulates the tracer transport online with the simulation of the atmospheric state by BRAMS, using the same dynamical and physical parameterizations. According to Freitas et al. (2009), the tracer mass mixing ratio, which is a prognostic variable, includes the effects of sub-grid-scale turbulence in the planetary boundary layer and convective transport by shallow and deep moist convection, in addition to grid-scale advective transport. The general mass continuity equation for tracers solved in the model, in tendency form, is

$$
\begin{aligned}
& \frac{\partial \bar{s}}{\partial t}=\left(\frac{\partial \bar{s}}{\partial t}\right)_{\mathrm{I}}^{\mathrm{adv}}+\left(\frac{\partial \bar{s}}{\partial t}\right)_{\mathrm{II}}^{\mathrm{PBL} \text { diff }}+\left(\frac{\partial \bar{s}}{\partial t}\right)_{\mathrm{deep} \mathrm{conv}}^{\mathrm{III}}+ \\
& \left(\frac{\partial \bar{s}}{\partial t}\right)_{\substack{\text { shallow conv } \\
\text { IV }}}+\left(\frac{\partial \bar{s}}{\partial t}\right)_{\mathrm{V}}+\underset{\mathrm{VI}}{W}+\underset{\mathrm{VII}}{R}+\underset{\mathrm{VIII}}{Q},
\end{aligned}
$$

where $\bar{s}$ is the mean mass mixing ratio, term (I) represents the 3-D advection, (II) is the sub-grid-scale diffusion in the PBL and terms (III) and (IV) are the sub-grid-scale transport by deep and shallow convection, respectively. Term (V) is the net production or loss by chemical reactions. Term (VI) is the wet removal, term (VII) refers to the dry deposition and, finally, (VIII) is the source term that includes the plume rise mechanism associated with vegetation fires (Freitas et al., 2007).

CCATT-BRAMS has two available advection schemes, one non-monotonic (Tremback et al., 1987) and another which has a monotonic (Freitas et al., 2012) formulation. The non-monotonic scheme uses a second order forwardupstream approximation. This formulation is simpler and faster for calculating scalar transport; however, it can generate non-physical negative mass concentrations and also new extrema. The monotonic scheme is more complex, but does not produce any new extrema (over- or undershoots) of the mass mixing ratio of the tracer being transported and also does not cause strong numerical diffusion. The diffusion in the PBL uses the same BRAMS formulations that are applied for temperature and water mass mixing ratio, but with a recent mass conservation fix on slopes developed by Meesters et al. (2008). As before, the same BRAMS convective parameterizations (for sub-grid-scale deep and shallow convection) applied to moist static energy and water vapor are applied consistently to the tracers. For radiative effects, smoke aerosols are assumed to be homogeneous spherical particles with an average mass density of $1.35 \mathrm{~g} \mathrm{~cm}^{-3}$, according to Reid et al. (1998). Size distribution and complex refractive index are based on climatological data from AERONET stations located in the Amazon basin and Cerrado and spectral optical properties were obtained using these climatologies as input in a Mie code (Procopio et al., 2003; Rosario et al., 2012). Wet removal of smoke aerosol particles is coupled with the deep convection parameterization following Berge (1993). Dry deposition is simulated using the resistance approach following Wesley (1989) and Seinfeld and Pandis (1998).

The CCATT model has also a preprocessor named PREPCHEM-SRC (Freitas et al., 2011), designed to produce emission fields of trace gases and aerosols for chemistry simulations. PREP-CHEM-SRC is able to generate emission fields from urban/industrial, biogenic, biomass burning, volcanic, biofuel use and burning from agricultural waste sources. The emission fields are generated on the native grid of the transport model and several map projections are available.

CCATT-BRAMS has been running operationally at CPTEC/INPE since 2003 in a domain that encompasses all of South America and with a spatial resolution of $25 \mathrm{~km}$. The predictions of gases and aerosols are available in real time at http://meioambiente.cptec.inpe.br/, and the meteorological variables are available at http://previsaonumerica.cptec.inpe. br/golMapWeb/DadosPages?id=CCattBrams.

\subsection{The JULES land surface component}

The Joint UK Land Environment Simulator is a soil/vegetation model developed from the Met Office Surface Exchange Scheme (MOSES) (Essery et al., 2003) and Top-down Representation of Interactive Foliage and Flora Including Dynamics (TRIFFID). MOSES is responsible for the simulation of surface energy fluxes and hydrological processes, and is the surface model used in the UK Met Office unified model (http://www.metoffice.gov. $\mathrm{uk} / \mathrm{research} /$ modelling-systems/unified-model). TRIFFID is designed to simulate vegetation and soil dynamics.

Figure 1 presents, in schematic form, the processes that are simulated by JULES version 3.0. Blue represents the processes that are related to hydrology, green refers to the processes that are directly involved with vegetation and brown 
refers to gases and aerosols. The lower layer of the diagram presents the processes that occur in the soil, the two upper layers refer to processes located between the surface and the canopy top and the arrows in the upper layer indicate fluxes, gases and aerosols that are exchanged with the atmosphere. The physics of JULES can be considered to fall into 5 areas. Below is a brief description of each area (the text is based on a documentation published at the link https://jules.jchmr.org/model-description, and further details can be obtained at Best et al., 2011, and Clark et al., 2011):

- Vegetation - Photosynthesis depends on the $\mathrm{CO}_{2}$ concentration of the environment and inside the leaf, as well as soil moisture and photosynthetically active radiation (PAR). The net primary production, derived of the plants respiration, can be divided into two processes: a fixed part for growth and the other for maintenance, wherein the maintenance is considered the concentration of nitrogen in the leaf. The vegetation dynamics module is responsible for updating the distribution of plants. It is considered a competition between vegetation types, depending on the net amount of carbon available and radiation PAR. Thus, there is a cocompetition depending mainly on relative heights of the plants, where trees (broadleaf and needleleaf) normally win out over grasses (type C3 (Collatz et al., 1991) and C4 (Collatz et al., 1992)). Therefore, the dominant types limit the expansion of subdominant types.

- Soil - The flux of water in the soil is given by the equation of Darcy, which depends on the hydraulic conductivity and soil water suction. The stock of carbon in the soil is increased by the total amount of leaves that fall on the ground and is reduced by soil respiration, which occurs at a rate dependent on the soil moisture and temperature.

- Hydrology - Part of the precipitation that arrives at the canopy is intercepted, while another part passes through the canopy and arrives at the soil (throughfall). Part of the water that arrives at the soil infiltrates and part runs off superficially (Gregory and Smith, 1990). This process is applied separately for each vegetation type. The model is being developed so that is will include a rainfall-runoff module and a runoff routing scheme.

- Radiation - Albedo of the bare soil varies geographically as a function of the soil color. For vegetation, the two flux model is used, calculating separately the direct and diffuse radiation albedos for each vegetation type.

- Energy balance - The evaporative flux extracted from each soil layer is dependent on the soil moisture availability factor. Evaporation from bare soil is extracted from the surface soil layer. The aerodynamic resistance for latent and sensible heat fluxes between the surface and the atmosphere above each vegetation type is calculated as a function of temperature, specific humidity and wind velocity.

JULES was conceived to serve two purposes: (1) to have a model freely available to the scientific community and (2) to permit model development to include new modules. The JULES source code is written in the FORTRAN90 language with a modular structure comprised of routines and subroutines. The land surface is divided in grid boxes, which can be occupied by a number of plant functional types (PFTs) and non-functional plant types (NPFTs). Up to five PFTs can occupy a grid box, whose names are broadleaf trees (BT); needleleaf trees (NT); $\mathrm{C} 3$ grasses $(\mathrm{C} 3 \mathrm{G})$; $\mathrm{C} 4$ grasses $(\mathrm{C} 4 \mathrm{G})$ and shrubs (Sh). A grid box can also be occupied by up to four NPFTs: urban, inland water, soil and ice. JULES adopts a tiled structure in which the surface processes are calculated separately for each surface type. It can be executed for a single point, for a group of points or for a regular grid.

The JULES model has been used in a large number of scientific studies, such as: (a) $\mathrm{CO}_{2}$ effects in continental rivers (Gedney et al., 2006), (b) dynamics of a vegetation model (Hughes et al., 2006), (c) interception of radiation and photosynthesis (Mercado et al., 2007), (d) impact of diffuse radiation on the land carbon sink (Mercado et al., 2009), and (e) ozone effects on the land carbon sink (Sitch et al., 2007), among others.

\subsection{The coupled JULES-CCATT-BRAMS system}

The JULES surface scheme has been fully coupled to the CCATT-BRAMS modeling system in an online fashion using an explicit scheme. The coupling is two-way in the sense that, for each model time step, the atmospheric component provides to JULES the current near-surface wind speed, air temperature, pressure, condensed water and downward radiation fluxes, as well as water vapor and trace gas (for example, carbon dioxide and monoxide, methane and volatile organic compounds) mixing ratios. After its processing, JULES advances its state variables over the time step and feeds back to the atmospheric component the sensible and latent heat and momentum surface fluxes, upward short-wave and longwave radiation fluxes, as well as a set of trace gas fluxes. Figure 2 shows a model grid box with the main physical and chemical processes that the JULES-CCATT-BRAMS system addresses.

JULES initialization requires: land use, soil type, normalized difference vegetative index (NDVI), sea surface temperature, soil carbon, soil moisture data and soil temperature. In this work, the land use map for the Amazon basin provided by the PROVEG project (Sestini et al., 2003) was used, while data from the RADAMBRASIL project (Rossato et al., 1998) was used for the soil type in Brazil and data from FAO (Zobler, 1999) was used outside Brazil. The 15-day NDVI data is derived from MODIS (Moderate Resolution Imaging Spectroradiometer) data based on the years 2001-2002. 


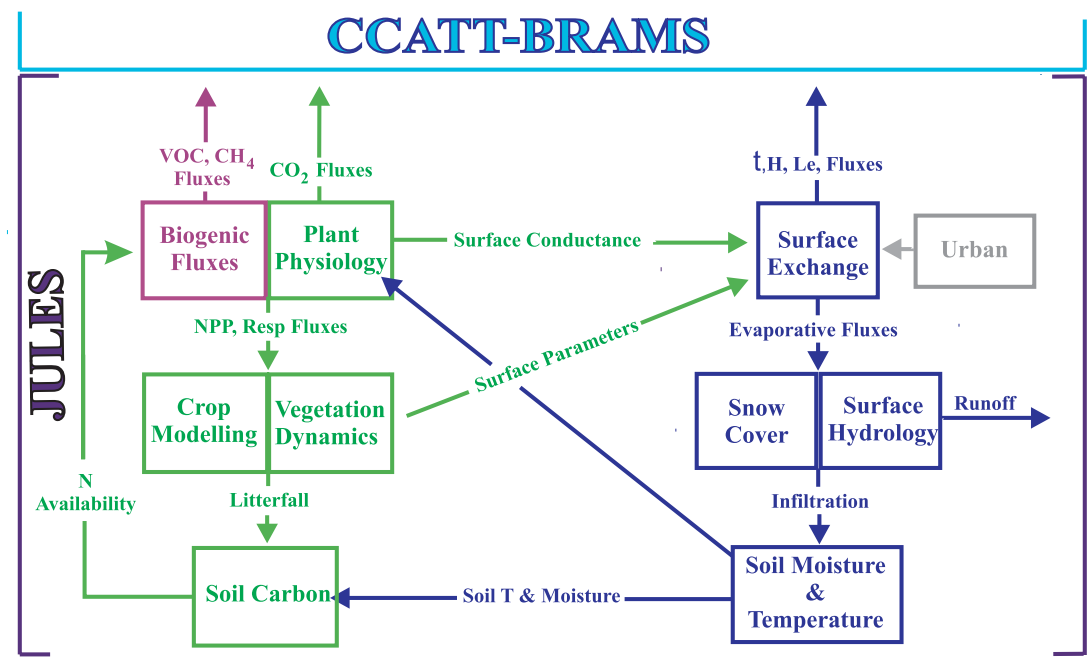

Fig. 1. Structure of JULES 3.0 (adapted from http://www.jchmr.org/jules/management/).

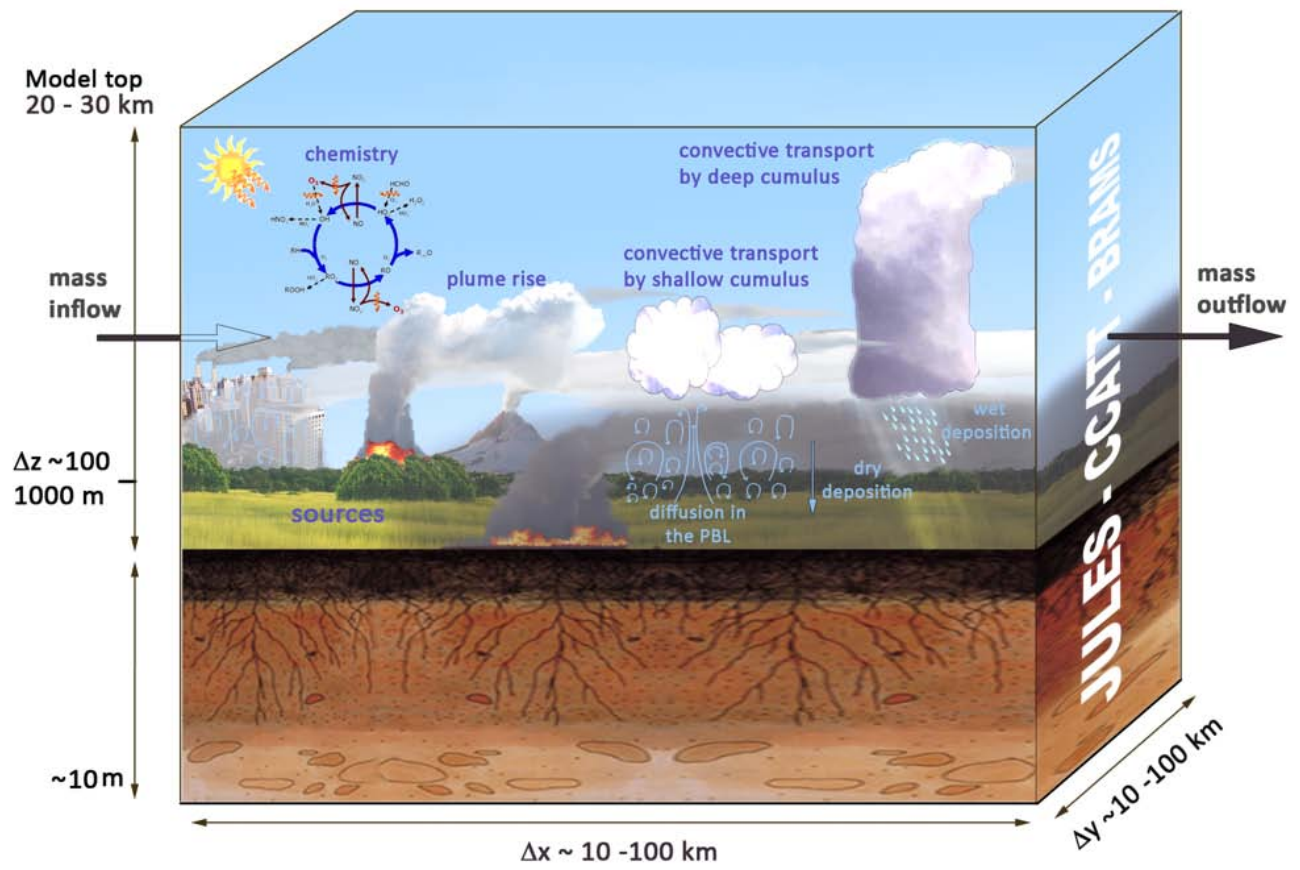

Fig. 2. Some of the sub-grid processes simulated by the JULES-CCATT-BRAMS model (adapted from http://meioambiente.cptec.inpe.br/ modelo_cattbrams.php).

Weekly sea surface temperature is provided by Reynolds et al. (2002) and observed soil carbon is provided by the LBA project (Large Scale Biosphere-Atmosphere Experiment in Amazonia) (Batjes, 1996). Daily soil moisture data, an operational product of CPTEC/INPE, is described by Gevaerd and Freitas (2006). Soil temperature is initialized with the air temperature of the first level of the atmospheric model.

CCATT-BRAMS requires topography data sets, an emissions database (urban/industrial, biogenic and biomass burning), atmospheric fields and the $\mathrm{CO}_{2}$ background. In this study, the Gesch et al. (1999) topography data set available through the United States Geological Survey's (USGS) Earth Resources Observation Systems (EROS) Data Center was used, with a latitude-longitude resolution of $30 \mathrm{arc}$ seconds (approximately $1 \mathrm{~km}$ ). Biomass burning emissions were estimated using fire pixels detected by remote sensing (GOES), and the other source emissions are climatological data sets (Freitas et al., 2011). The atmospheric fields for initialization and boundary conditions were obtained from the National Centers for Environmental Prediction 
(NCEP) final analysis (FNL) with a T382 horizontal resolution (approximately $35 \mathrm{~km}$ ) and 64 vertical pressure levels at $6 \mathrm{~h}$ time intervals (available online at $\mathrm{ftp}: / / \mathrm{ftpprd}$. ncep.noaa.gov/pub/data/nccf/com/gfs/prod/), which were interpolated to the model grid. Initial and boundary conditions for $\mathrm{CO}_{2}$ were taken from outputs of the CarbonTracker/TM5 carbon data assimilation system (Krol et al., 2005; Peters et al., 2007) with a horizontal resolution of $3^{\circ} \times 2^{\circ}$ and 34 vertical levels (http://www.esrl.noaa.gov/gmd/ ccgg/carbontracker/documentation_4pdf.html).

The processing time for JULES-CCATT-BRAMS in relation to CCATT-BRAMS was increased by around $17 \%$. This cost is very low considering that JULES simulates more processes than LEAF, predicts gas concentrations and includes variations in vegetation morphology over the simulation time; and it is shown in this work that there is a significant gain in quality by using JULES when compared with LEAF.

\section{Evaluation and sensitivity tests}

In order to evaluate the JULES-CCATT-BRAMS system, 183 simulations were conducted in forecast mode. Regional numerical weather forecasts typically have integration times ranging from 1 to 7 days; thus, in this evaluation each simulation was integrated for 5 days. 93 simulations ( 3 experiments with 31 members each, one member per day) were conducted for March 2010 (wet season) and 90 (3 experiments with 30 members each) for September 2010 (dry season).

In Table 1, the principal CCATT-BRAMS model configurations and parameterizations are defined, and Table 2 presents the configurations and parameterizations that were altered in relation to the namelist point_loobos_example.jin that accompanies the version 3 of the JULES package.

The simulations were executed on a CRAY cluster (2.1 GHz AMD Opteron processors) using 360 processors. The processing time for each 5-day simulation was approximately 48 min using LEAF and 56 min using JULES.

\subsection{Data for evaluation}

To evaluate JULES-CCATT-BRAMS, the following data were used:

- METAR and PCDs: Observations from surface meteorological stations installed at airports (METAR) and automatic stations (PCDs) installed and maintained by the National Institute of Meteorology (INMET). These data have a temporal frequency of one hour and an irregular spatial distribution. They are available daily on the respective websites: http://www.redemet. aer.mil.br and http://www.inmet.gov.br/sonabra/maps/ automaticas.php.

- Km 67 tower: Observed data measured by an eddy correlation system installed at a meteorological tower at an altitude of $57.9 \mathrm{~m}$. This tower is located to the south of Santarém, PA, Brazil, close to kilometer 67 of the Cuiabá-Santarém highway (Tapajós forest: $55.04^{\circ} \mathrm{W}$, $2.85^{\circ} \mathrm{S}$ ). These data were collected in an automatic and continuous way starting in August 2008 with a temporal resolution of $1 \mathrm{~h}$.

- Airplane: Observed data collected aboard an airplane. 80 profiles were performed during the year 2010 in a descending spiral profile from $4300 \mathrm{~m}$ to $300 \mathrm{~m}$ in four Amazon locations: Santarém, PA (SAN); Rio Branco, AC (RBA); Alta Floresta, MT (ALF); and Tabatinga, $\mathrm{AM}(\mathrm{TAB})$. All profiles were usually taken between 12 and $14 \mathrm{~h}$ local time. At the RBA, TAB and ALF sites, 12 flasks were sampled with a portable sampling system consisting of separate compressor and flask units. These units were loaded onto a light aircraft. A GPS and temperature and relative humidity sensors were also attached to the compressor unit. The pilot initiated sample collection at a pre-determined altitude using a wired remote control. At SAN the flask unit contained 17 flasks, and for all units each flask had a volume of $700 \mathrm{~mL}$ and was pressurized to about $270 \mathrm{kPa}$, as described in Gatti et al. (2010).

- ECMWF: ECMWF ERA-Interim reanalysis (Dee et al., 2011). This reanalysis has a horizontal resolution of $1.5^{\circ}$ and utilizes a 4-D-Var system (Bouttier and Kelly, 2001) to assimilate observed data (available online at http://data-portal.ecmwf.int/data/d/interim_daily/ levtype $=\mathrm{sfc} /$ ).

\subsection{Applications in numerical weather prediction}

The data obtained from numerical simulations were compared with METAR and PCD data.

The simulated values of air and dew point temperature at $2 \mathrm{~m}$, wind speed at $10 \mathrm{~m}$, and precipitation were bilinearly interpolated to the station points using the four grid points around the station point. With the simulated and observed data collocated at each grid point, the bias and root-meansquared error (RMSE) were calculated utilizing Eqs. (2) and (3), respectively. Figure 3 presents in a schematic form the methodology utilized to obtain the error plots presented in this work. For each station and hour of integration $(0$, $1,2, \ldots, 120)$, bias and root-mean-squared error between the observed and simulated data were calculated using 30 (or 31) members, and the arithmetic mean of the errors at all stations in the desired domain was calculated. The spatial distribution of observed data is described in Fig. 4a. The first two days of integration were ignored, the period in which the model is in adjustment, and the mean of the last three days was calculated. In this way, the plot of the evolution of the error along the day for a certain variable and a certain experiment is obtained. This methodology is used 
Table 1. Main parameters and parameterizations used in the CCATT-BRAMS model.

\begin{tabular}{|c|c|}
\hline CCATT-BRAMS version: & 4.3 .3 \\
\hline Atmospheric boundary conditions: & TQ0382L064 (horizontal resolution of the $\sim 35 \mathrm{~km}$ and 64 vertical levels) \\
\hline Horizontal resolution: & $20 \mathrm{~km}$ \\
\hline Points in $\mathrm{X}$ : & 310 \\
\hline Points in Y: & 210 \\
\hline Points in Z: & 48 \\
\hline Points in soil level: & 7 \\
\hline Time step : & $30 s$ \\
\hline Grid center: & $59.0^{\circ} \mathrm{W}, 3.2^{\circ} \mathrm{S}$ \\
\hline \multirow[t]{3}{*}{ Nudging in domain: } & Lateral: $900 \mathrm{~s}$ (15 points) \\
\hline & Center: $43200 \mathrm{~s}$ \\
\hline & Top: $10800 \mathrm{~s}$ (above of $15 \mathrm{~km}$ ) \\
\hline Cumulus convection (deep/shallow): & Grell and Dezso Devenyi (2002)/Souza (1999) \\
\hline Radiation: & CARMA (Toon et al., 1988) \\
\hline Vertical coordinate: & Sigma-z \\
\hline Basic equations: & Non-hydrostatic \\
\hline Topography scheme: & Average orography \\
\hline Turbulent diffusion: & Mellor and Yamada (Mellor and Yamada, 1982) \\
\hline Microphysics: & Complexity level 3 (Flatau et al., 1989) \\
\hline Topography map: & USGS (1 km of resolution) (Gesch et al., 1999) \\
\hline SST: & Weekly from the NCEP (111 km of resolution) (Reynolds et al., 2002) \\
\hline Land use map: & OGE (outside Brazil) + IBGE/INPE (within Brazil) (1 km resolution) (Olson, 1994; Sestini et al., 2003) \\
\hline Soil type: & FAO-INPE (55 km of resolution) (Zobler, 1999; Rossato et al., 1998) \\
\hline NDVI: & From MODIS (1 km of resolution) \\
\hline Soil moisture: & CPTEC/INPE (28 km of resolution) (Gevaerd and Freitas, 2006) \\
\hline Output frequency: & $1 \mathrm{~h}$ \\
\hline Time of integration: & $120 \mathrm{~h}$ (5 days) \\
\hline Number of CPUs: & 360 \\
\hline
\end{tabular}

Table 2. Main parameters in the JULES namelist that were changed in relation to the example point_loobos_example.jin (included in jules_3.0 source).

\begin{tabular}{ll}
\hline nxIn, nyIn: & 310,210 (from CCATT-BRAMS namelist) \\
sm_levels: & 7 (from CCATT-BRAMS namelist) \\
can_rad_mod: & 4 \\
timestep: & $30 \mathrm{~s}$ (from CCATT-BRAMS namelist) \\
dateMainRun: & "mar/2010 and sep/2010" (from CCATT-BRAMS namelist) \\
pointsList: & $\mathrm{T}$ \\
readFileLand: & $\mathrm{T}$ (from CCATT-BRAMS) \\
regLatLon: & $\mathrm{T}$ \\
cs: & LBA Project (Batjes, 1996) \\
readFile (INIT_LATLON): & $\mathrm{T}$ (from CCATT-BRAMS) \\
readFile (INIT_FRAC): & $\mathrm{T}$ (from CCATT-BRAMS) \\
readFile (INIT_SOIL): & $\mathrm{T}$ (from CCATT-BRAMS) \\
dzsoil: & $0.1,0.25,0.65,1.25,2.0,3.0,5.0$ \\
rootd_ft: & $5.00,1.00,0.50,0.50,0.50$ \\
driveDataPer: & $30 \mathrm{~s}(=$ timestep) (from CCATT-BRAMS) \\
ioPrecipType: & 1 \\
ioWindSpeed: & $\mathrm{F}$ \\
z1_uv, z1_tq: & Height of the first CCATT-BRAMS level $-z_{\mathrm{o}}$ (zero plane) \\
\hline
\end{tabular}

by CPTEC/INPE to validate weather forecasts produced by several research centers (http://intercomparacaodemodelos. cptec.inpe.br/phps/vies_emq/).
The Eqs. (2) and (3) describe respectively the procedure used to obtain the bias and root-mean-squared error of the 


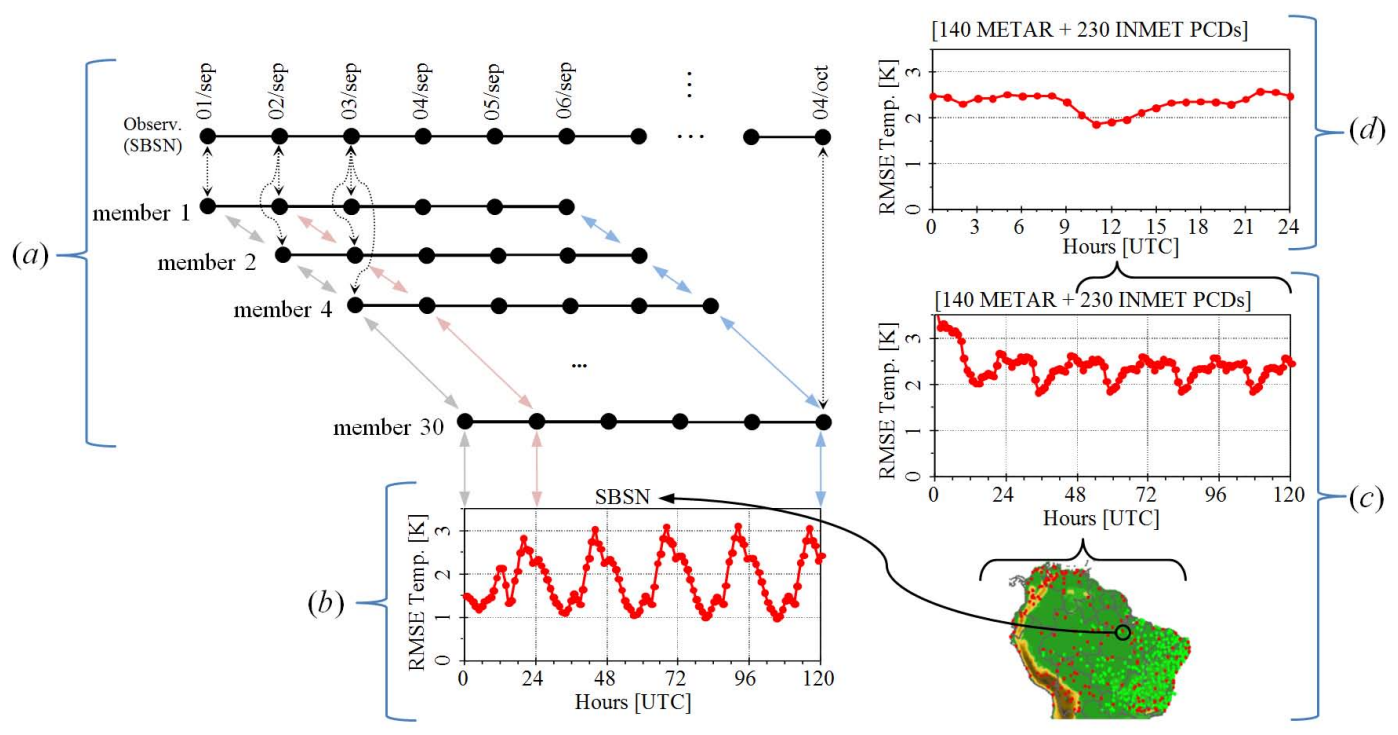

Fig. 3. Method for evaluation of the simulations. (a) Simulated data of each member is compared with observed data from similar time; (b) obtain RMSE (or BIAS) to $120 \mathrm{~h}$ of model integrate for each station; (c) arithmetic mean of the errors at all stations in the desired domain is calculated; and (d) the first two days of integration are ignored and the mean of the last three days is calculated.

simulations.

$\operatorname{BIAS}(h)=\frac{\sum_{d=3}^{D} \frac{\sum_{s=1}^{S} \frac{\sum_{m=1}^{M}\left(\operatorname{model}\left(m, s, h_{(m, d)}\right)-\mathrm{obs}\left(s, h_{(m, d)}\right)\right)}{M}}{S}}{D}$

$\operatorname{RMSE}(h)=\frac{\sum_{d=3}^{D} \frac{\sum_{s=1}^{S} \sqrt{\frac{\sum_{m=1}^{M}\left(\operatorname{model}\left(m, s, h_{(m, d)}\right)-\operatorname{obs}\left(s, h_{(m, d)}\right)\right)^{2}}{M}}}{S}}{D}$

where

$m=$ member of the month $(1,2, \ldots, 30$ (or 31)),

$M=$ number of members (31 in March and 30 in

September),

$s=$ stations in selected region $(\mathrm{SBMN}, \mathrm{A} 701, \ldots)$,

$S=$ number of stations in selected region (METAR+INMET

PCDs),

$d=$ days of integration (3, 4 and 5),

$D=$ number of days of integrations $(D=5)$, and

$h=$ hours (UTC) of the day $(00,01, \ldots, 23)$.

\subsubsection{Evaluation of the numerical forecast during March 2010 (wet season)}

For the rainy season, three experiments were conducted in order to evaluate the JULES-CCATT-BRAMS system:

- Using the original soil-vegetation model (LEAF) with a non-monotonic advection scheme (ad0) and disregard- ing the presence of aerosol (ae0), which is symbolized by LEAF_ad0_ae0,

- Similar to the previous, but using the JULES soil-vegetation model, which is symbolized by JULES_ad0_ae0,

- Similar to the previous, but with a monotonic advection scheme (ad1), which is symbolized by JULES_ad1_ae0.

The error of the ECMWF reanalysis was also calculated, following the same methodology described above.

Figure 4 shows the root-mean-squared error considering the mean errors at the METAR and INMET PCD stations contained in the entire domain of the simulations (Fig. 4a). Daily data from around 70 to 200 stations were used, depending on the evaluated variable. Table 3 also shows the errors at 06:00 UTC (night period), at 18:00 UTC (daylight period) and the daily mean (these are the same values shown in Fig. 4). Considering the temperature at $2 \mathrm{~m}$, it can be observed in Fig. $4 \mathrm{~b}$ that during the nocturnal period the coupling with JULES, with both transport configurations, monotonic and non-monotonic, had a similar error to the model with LEAF. However, during the daytime the model with JULES presented much better results for temperature, above all when the monotonic scheme was utilized. ECMWF data presents the lowest and the highest RMSE during the night and day, respectively. The best overall score is presented by JULES with a mean RMSE equal to 1.80 , followed by ECMWF and LEAF with 1.96 and 1.97, respectively. The bias analysis pointed out that the model with JULES (in both transport configurations) and ECMWF have biases close to zero during the nighttime and negative bias during the 

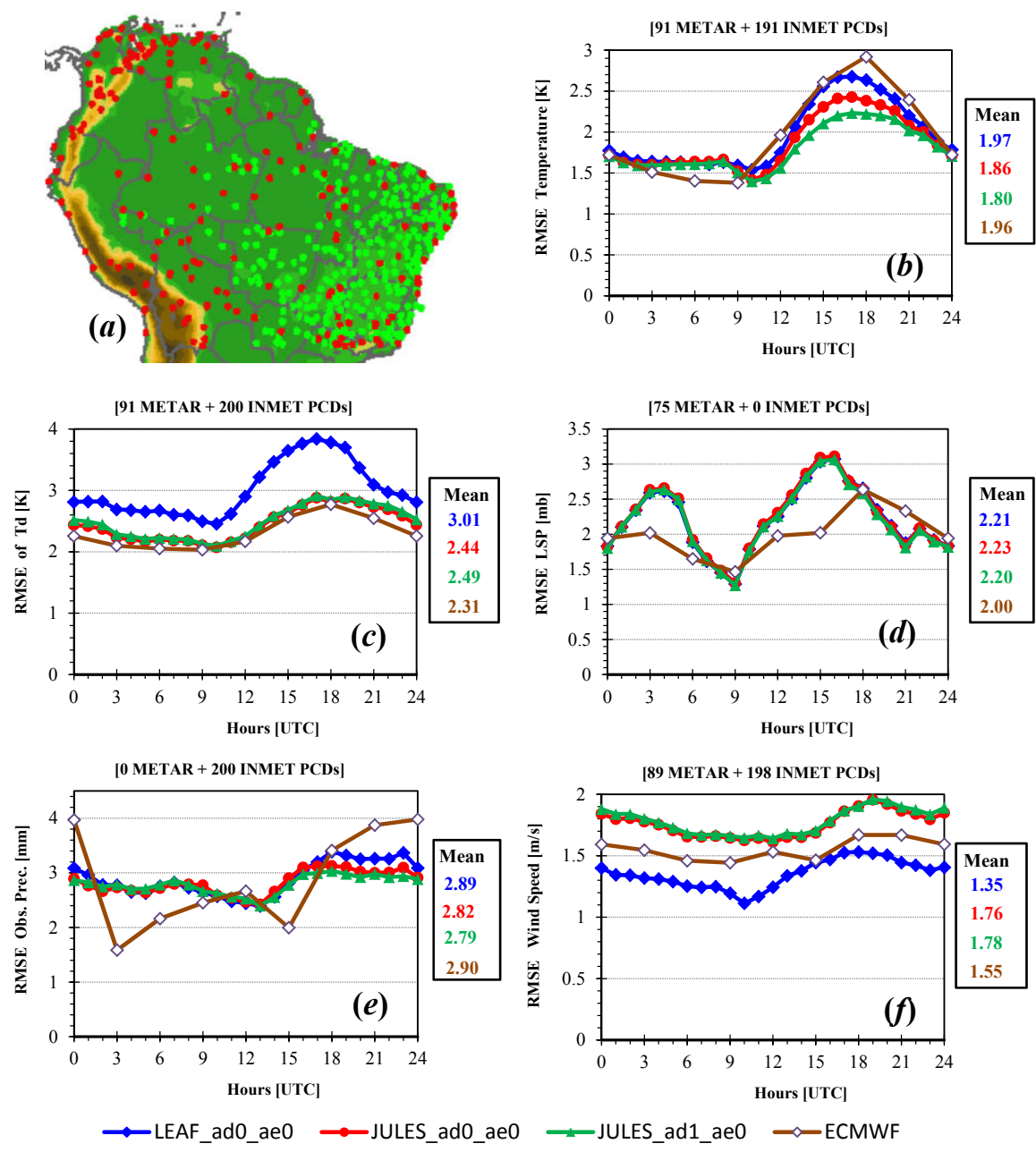

Fig. 4. Geographic locations of the conventional airport stations (red points) and automatic stations (green points) (a). Root-mean-squared error for the variables: air temperature at $2 \mathrm{~m} \mathrm{(b);} \mathrm{dew} \mathrm{point} \mathrm{temperature} \mathrm{at} 2 \mathrm{~m}$ (c); pressure reduced to mean sea level (d); six-hour accumulated precipitation (e); and wind speed at $10 \mathrm{~m}$ (f) - for the period from 1 to 31 March 2010. Brown line refers to ECMWF reanalyses and other lines are from JULES-CCATT-BRAMS model disregarding the presence of aerosol (ae0), where the blue and red lines used LEAF and JULES surface model with non-monotonic advection (ad0), respectively, and the green line used JULES surface model with monotonic advection $(\operatorname{ad} 1)$.

daytime, while the model with LEAF has a positive bias during the nighttime and negative bias during the day. The bias figures are not shown, but the values shown in Table 3 at 06:00 UTC and 18:00 UTC represent well what occurred in the night and daylight periods, respectively. For example, at 06:00 UTC the temperature biases for the two JULES configurations were -0.14 and 0.02 , for ECMWF the bias was -0.05 and for LEAF it was 0.60 . At 18:00 UTC they were $-1.01,-0.63,-1.77$ and -0.70 , respectively.

The improvement from coupling CCATT-BRAMS with JULES is much higher for the dew point temperature at $2 \mathrm{~m}$ (Td), as shown in Fig. 4c. The mean RMSE dropped from 3.01 to 2.44 . Note also that the use of a monotonic advection scheme did not make any difference in this evaluation. In this case, ECMWF presents the lowest mean RMSE, with
JULES much closer to it than LEAF. For the mean sea level pressure (LSP), the coupling with JULES did not present noticeable improvement, as one can see from Fig. 4d. For precipitation, JULES had a smaller error than LEAF during the daytime, as shown in Fig. 4e. The monotonic advection scheme results in a slightly better score (2.79), which might be related to more accurate moisture transport. JULES also provides a better performance than ECMWF. In terms of the wind speed at $10 \mathrm{~m}$ above the surface, the results are very different (Fig. 4f). LEAF provides the best score, even better than ECMWF reanalysis data. However, the results are different for simulated wind speed at the levels above the surface, as shown in Fig. 5. This figure shows the wind speed RMSE using radiosoundings at 11 locations during March 2010. RMSEs are similar for all models, with the JULES 
Table 3. Error values for the night period (06:00 UTC), daytime period (18:00 UTC) and daily mean (DM) during the wet season (March 2010).

\begin{tabular}{|c|c|c|c|c|c|c|c|c|c|c|c|c|c|}
\hline & & \multicolumn{3}{|c|}{ LEAF_ad0_ae0 } & \multicolumn{3}{|c|}{ JULES_ad0_ae0 } & \multicolumn{3}{|c|}{ JULES_ad1_ae0 } & \multicolumn{3}{|c|}{ ECMWF } \\
\hline & & 06 & 18 & $\mathrm{DM}$ & 06 & 18 & $\mathrm{DM}$ & 06 & 18 & $\mathrm{DM}$ & 06 & 18 & $\mathrm{DM}$ \\
\hline \multirow{5}{*}{ RMSE } & Temp. & 1.62 & 2.63 & 1.97 & 1.64 & 2.38 & 1.86 & 1.61 & 2.22 & 1.80 & 1.40 & 2.92 & 1.96 \\
\hline & $\mathrm{Td}$ & 2.67 & 3.78 & 3.01 & 2.20 & 2.81 & 2.44 & 2.23 & 2.84 & 2.49 & 2.05 & 2.77 & 2.31 \\
\hline & LSP & 1.89 & 2.65 & 2.21 & 1.92 & 2.64 & 2.23 & 1.90 & 2.59 & 2.20 & 1.65 & 2.64 & 2.00 \\
\hline & Prec. & 2.76 & 3.39 & 2.89 & 2.72 & 3.12 & 2.82 & 2.78 & 3.03 & 2.79 & 2.16 & 3.41 & 2.90 \\
\hline & Wind & 1.25 & 1.53 & 1.35 & 1.65 & 1.90 & 1.76 & 1.68 & 1.90 & 1.78 & 1.46 & 1.67 & 1.55 \\
\hline \multirow{5}{*}{ BIAS } & Temp. & 0.60 & -0.70 & 0.05 & -0.14 & -1.01 & -0.45 & 0.02 & -0.63 & -0.20 & -0.05 & -1.77 & -0.64 \\
\hline & $\mathrm{Td}$ & 1.90 & 2.82 & 2.00 & 1.21 & 1.72 & 1.44 & 1.36 & 1.78 & 1.57 & 1.11 & 1.29 & 1.08 \\
\hline & LSP & -1.63 & -2.35 & -1.64 & -1.67 & -2.34 & -1.65 & -1.66 & -2.30 & -1.62 & -0.93 & -2.37 & -1.36 \\
\hline & Prec. & 1.47 & 2.39 & 1.83 & 1.42 & 2.10 & 1.72 & 1.44 & 2.01 & 1.67 & 1.38 & 2.80 & 2.23 \\
\hline & Wind & 0.61 & -0.53 & 0.14 & 1.20 & 0.92 & 1.10 & 1.23 & 0.96 & 1.14 & 0.76 & 0.01 & 0.52 \\
\hline
\end{tabular}

simulation with monotonic advection showing slightly better scores. This result suggests that the differences in RMSE of wind speed at $10 \mathrm{~m}$ could be related to physical formulations used by both surface schemes to derive the wind speed at this level. It could also be observed in the bias figure (not shown) and Table 3 that both the JULES experiments and ECMWF overestimated the wind speed at $10 \mathrm{~m}$ above the surface, and the experiment with LEAF overestimated it in the night period and underestimated it in the daytime period.

\subsubsection{Evaluation of the numerical forecast during September (dry season)}

The dry season (July-September) in South America (SA) corresponds to austral winter. This season is discernible by suppression of rainfall over large areas of SA and by the huge number of vegetation fires along the border of the Amazon region and in central Brazil. The associated smoke is transported and dispersed over large areas of SA (Freitas et al., 2005) with significant effects on air quality, the regional energy budget (Procopio et al., 2003; Rosário et al., 2012) and very likely on the hydrological cycle (Andreae et al., 2004). As previously discussed, the two latter aspects are strongly linked to surface processes, either as drivers or as responses. Therefore, a special aspect we evaluate for September 2010 is the importance of the inclusion of the biomass burning aerosol direct radiative effect on radiative transfer. Here we present model evaluations for September 2010 using the same observational data as presented in Fig. 4a. The simulations are named as follows:

- LEAF_ad0_ae0: using the original soil-vegetation scheme (LEAF), with a non-monotonic advection scheme (ad0) and disregarding the presence of atmospheric biomass burning aerosol (ae0),

- JULES_ad0_ae0: the same as above, but using JULES,

- JULES_ad0_ae1: using JULES, a non-monotonic advection scheme (ad0) and including the direct radiative ef-

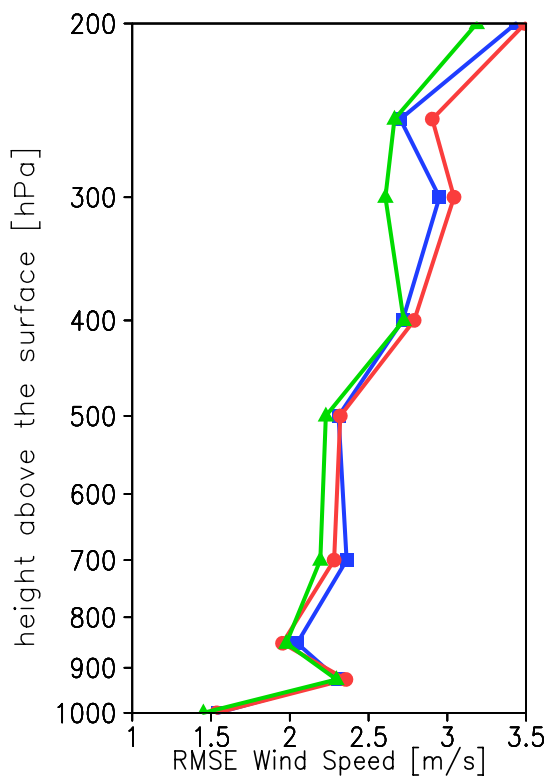

Fig. 5. Root-mean-squared error of wind speed, considering radiosounding data measured daily at $12 \mathrm{Z}$ at 11 stations, during the 31 days of the month of March 2010.

fect of smoke aerosols (radiation absorption and scattering) (ae1).

As before, we also include ECMWF reanalysis data to compare with our results.

Figure 6 shows the results for (a) temperature and (b) dew point temperature at $2 \mathrm{~m}$, as well as (c) precipitation and (d) wind speed at $10 \mathrm{~m}$. For the first two quantities, JULES presents a noticeable gain in performance with scores closer to the ECMWF ones. However, there is not any discernible improvement of the precipitation forecasts (c), with ECMWF having the best score. As before, LEAF presents a better score for wind speed at $10 \mathrm{~m}$, even better than ECMWF results. In Table 4 is possible to observe that the experiments 

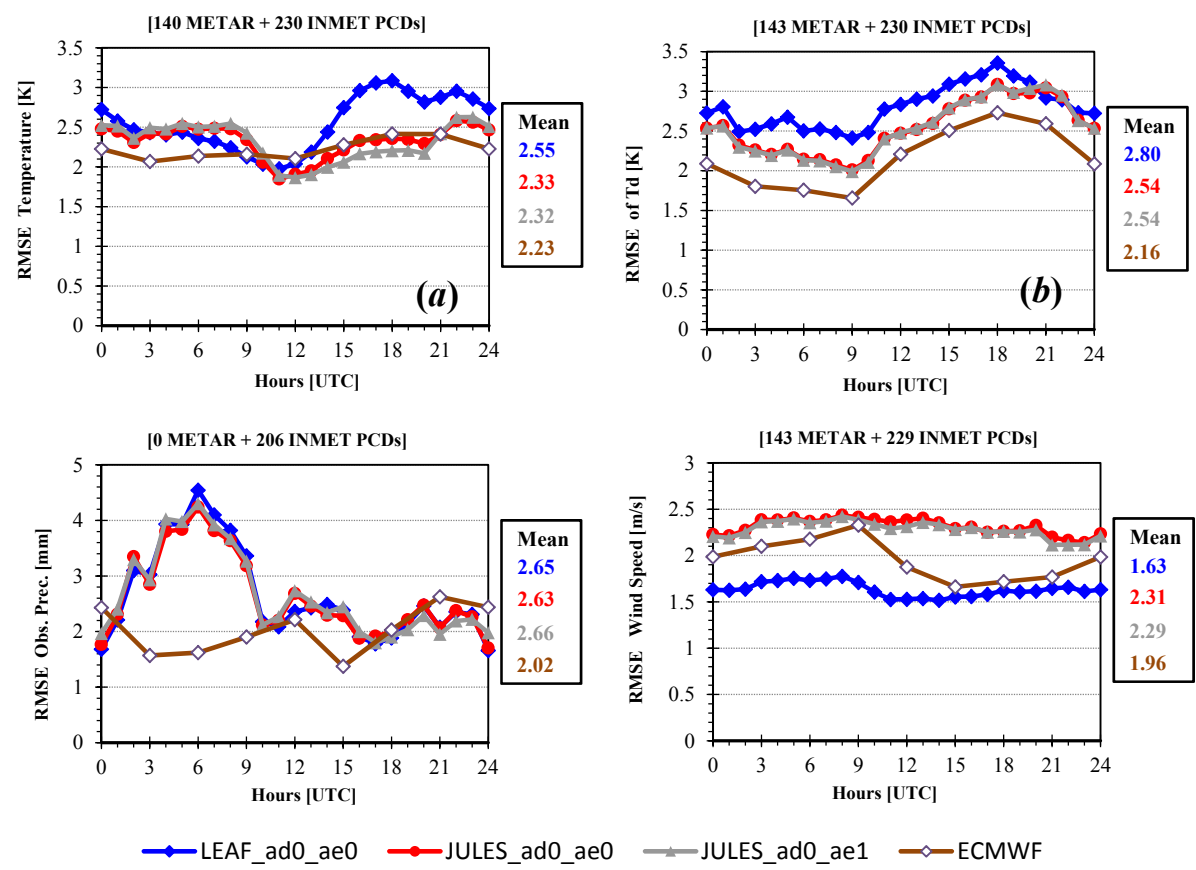

Fig. 6. Similar to Fig. 4, but for the dry season (September 2010): (a) air temperature at $2 \mathrm{~m}$; (b) dew point temperature at $2 \mathrm{~m}$; (c) sixhour accumulated precipitation and (d) wind speed at $10 \mathrm{~m}$. The gray line is from the JULES-CCATT-BRAMS model with non-monotonic advection (ad0), using JULES surface model and considering the presence of aerosol (ae1).
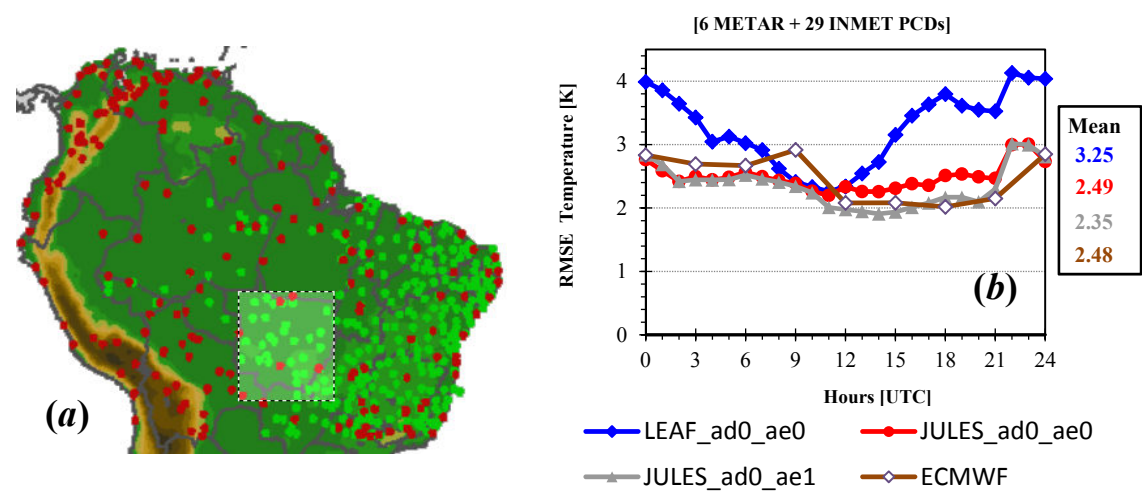

Fig. 7. Root-mean-squared error of air temperature at $2 \mathrm{~m}$ in September 2010. The average is calculated only for the stations within the lighter rectangle in the figure on the right (6 METAR stations and 29 INMET PCDs).

with JULES obtained the bias closest to zero in temperature at $2 \mathrm{~m}$, while the experiment with LEAF obtained a positive bias for all diurnal cycles and the ECMWF bias was positive in the night period and negative in daytime. Tables 3 and 4 also show that LEAF presents a lower bias than the others.

As previously mentioned, this case study can be used to evaluate the impact of biomass burning aerosols on nearsurface atmospheric properties. Observing Fig. 6 again, one can see that the inclusion of biomass burning aerosols results in slightly better scores for temperature at $2 \mathrm{~m}$, wind speed at $10 \mathrm{~m}$ and dew point temperature, and an equal score for precipitation. However, focusing on the evaluation over a smaller area where the smoke concentrates, the impacts are much higher, as expected. Figure 7a shows a smaller domain with the highest aerosol concentration in September as simulated by the JULES-CCATT-BRAMS model. The monthly mean column amount of particulate matter less than $2.5 \mu \mathrm{m}$ $\left(\mathrm{PM}_{2.5}\right)$ in the area shown in Fig. 7a is $62 \mathrm{mg} \mathrm{m}^{-2}$ (in March, wet season, this value was $8 \mathrm{mg} \mathrm{m}^{-2}$ ). Figure $7 \mathrm{~b}$ presents the RMSE of temperature at $2 \mathrm{~m}$ for this area. The improvement during the daytime is evident, with a decrease in the mean score from 2.49 (JULES_ad0_ae0) to 2.35 (JULES_ad0_ae1). Note also that only the use of JULES caused a huge gain in performance in the RMSE, which dropped from 3.25 
Table 4. Error values for the night period (06:00 UTC), daytime period (18:00 UTC) and daily mean (DM) for the dry season (September 2010).

\begin{tabular}{|c|c|c|c|c|c|c|c|c|c|c|c|c|c|}
\hline & & \multicolumn{3}{|c|}{ LEAF_ad0_ae0 } & \multicolumn{3}{|c|}{ JULES_ad0_ae0 } & \multicolumn{3}{|c|}{ JULES_ad0_ae1 } & \multicolumn{3}{|c|}{ ECMWF } \\
\hline \multirow{4}{*}{ RMSE } & Temp. & 2.26 & 2.99 & 2.55 & 2.26 & 2.21 & 2.33 & 2.28 & 2.14 & 2.32 & 2.14 & 2.41 & 2.23 \\
\hline & LSP & 3.05 & 3.29 & 2.13 & 3.06 & 3.30 & 3.15 & 3.06 & 3.30 & 3.15 & 2.83 & 3.04 & 2.88 \\
\hline & Prec. & 3.90 & 2.12 & 2.65 & 3.78 & 2.21 & 2.63 & 3.78 & 2.10 & 2.66 & 1.62 & 2.03 & 2.02 \\
\hline & Wind & 1.73 & 1.61 & 1.63 & 2.45 & 2.33 & 2.31 & 2.44 & 2.33 & 2.29 & 2.18 & 1.72 & 1.96 \\
\hline \multirow{4}{*}{ BIAS } & $\mathrm{Td}$ & 0.43 & 1.59 & 0.75 & 0.80 & 1.58 & 1.04 & 0.77 & 1.63 & 1.06 & 0.14 & 0.68 & 0.24 \\
\hline & LSP & -0.33 & 0.49 & -0.27 & -0.26 & 0.40 & -0.26 & -0.23 & 0.44 & -0.23 & -0.18 & -0.15 & -0.32 \\
\hline & Prec. & -0.56 & 1.26 & 0.54 & -0.77 & 1.36 & 0.57 & -0.83 & 1.25 & 0.51 & 0.76 & 1.74 & 1.37 \\
\hline & Wind & 1.04 & -0.39 & 0.41 & 1.99 & 1.45 & 1.75 & 1.98 & 1.44 & 1.73 & 1.64 & 0.18 & 1.05 \\
\hline
\end{tabular}

(with LEAF) to 2.49. Finally, the ECMWF reanalysis had a score similar to JULES_ad0_ae0, and it also does not include aerosol direct effects on radiation, at least not in the level of detail that JULES-CCATT-BRAMS did here. For the other variables (dew point temperature at $2 \mathrm{~m}$, rainfall and wind speed) significant differences were not observed between JULES_ad0_ae0 and JULES_ad0_ae1 (not shown). The differences between LEAF, JULES (ae0 or ae1) and ECMWF were also similar to the result shown before with the average at all stations (Fig. 6).

\subsubsection{NCEP bias}

Figure 8 presents the mean bias for temperature at $2 \mathrm{~m}$ of the NCEP analysis, which was utilized as the initial and boundary conditions of the simulations. This bias was calculated in relation to the observed data from METAR and INMET PCD stations during the month of March 2010. The colors in blue tones, represented with a circle around the station location, correspond to negative bias (underestimated temperature), and the colors in red tones, represented with squares, correspond to positive bias (overestimated temperature). The numbers inside the circles (or squares) represent the predominant vegetation type at the station point. It can be observed that the errors are high, above all during early morning (12:00 UTC, 8 a.m. LT). In certain regions, values are larger than $4{ }^{\circ} \mathrm{C}$ and in other regions lower than $-4^{\circ} \mathrm{C}$. It is also noted that a region with negative bias (northeast region of Brazil, except the coast) and another with a positive bias (Amazon region) are well characterized. During the nighttime (00:00 UTC, 8 p.m. LT) normally a negative bias is observed, with exception of the northeast Brazilian coast and some stations in the Amazon region. We were unable to identify a relationship between NCEP bias and vegetation type.

Zhang et al. (2006), using the MM5 mesoscale model, showed that small-amplitude initial errors can grow rapidly and, subsequently, contaminate the short-term deterministic mesoscale forecast within $36 \mathrm{~h}$. Xu and Zhong (2009) also found similar results using the Weather Research and Forecasting (WRF) model. Therefore, part of the simulation errors are probably associated with the inherent errors in the NCEP analyses, utilized as initial and boundary conditions, since the JULES-CCATT-BRAMS simulations were executed without assimilation of observations.

\subsection{Simulating the carbon cycle over the Amazon}

Soil processes, such as stocks of carbon and humidity, are quite slow processes. However, in modeling a technique of "denominated spin-up" is normally used. This technique consists of executing a model for several years until the changes in the fields are less than a certain delta, considering that at this point the model is in equilibrium (Yang et al., 1995). To attain this equilibrium it is necessary to run the model for several years. However, this is a very computationally expensive process, and in the case of this study this was a difficult technique to apply, due to the large number of points to be simulated. With the aim of reducing the necessity of spin-up, in this study we initialize the model with fields as close as possible to observations, such as observed values of soil carbon content (Batjes, 1996) and soil moisture estimated via an off-line water balance model forced with rainfall derived from remote sensing (Gevaerd and Freitas, 2006).

\subsubsection{Evaluating model simulations of atmospheric $\mathrm{CO}_{2}$ profiles}

To evaluate the ability of the JULES-CCATT-BRAMS modeling system to reproduce observed $\mathrm{CO}_{2}$ profiles, the profiles from airplane data described in Sect. 3.1 were used.

Figure 9 presents eight $\mathrm{CO}_{2}$ concentration profiles for wet (a, b, c and d) and dry (e, f, g and h) seasons, two of them for each location described above. The figure shows aircraft observed $\mathrm{CO}_{2}$ concentration, numerical results of $\mathrm{CO}_{2}$ concentration with the JULES-CCATT-BRAMS model as well 

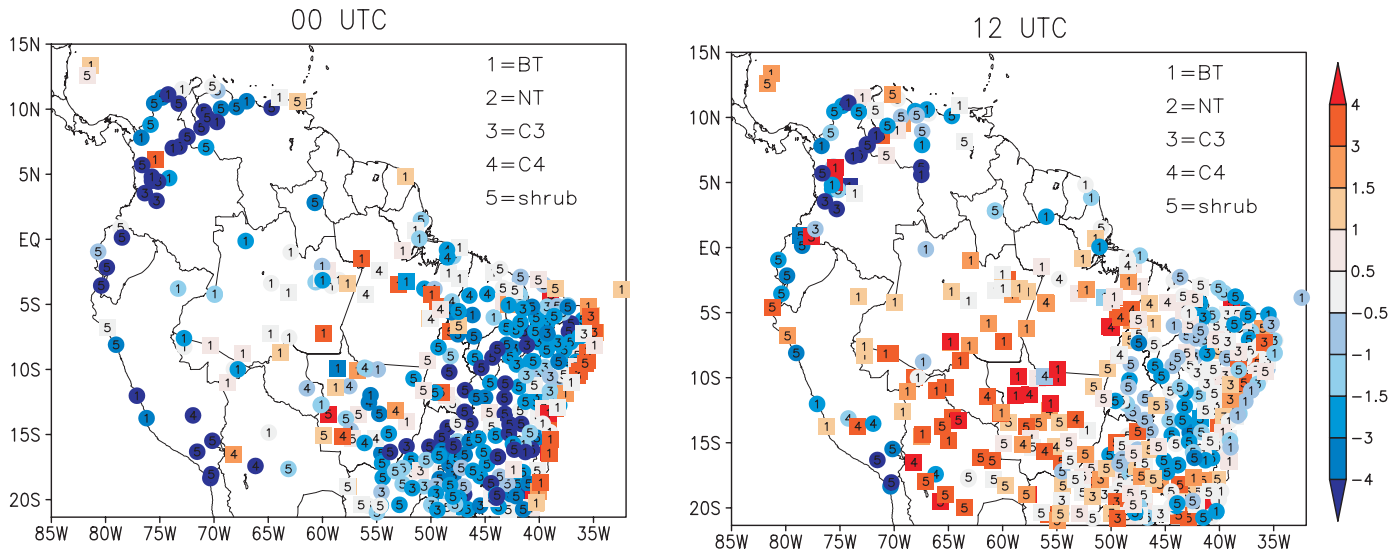

Fig. 8. The colors represent the bias NCEP analysis (average difference between NCEP analysis and observation) at 00:00 UTC and 12:00 UTC. The numbers inside the circles (or squares) represent the predominant vegetation type at the station point, where BT $=$ broadleaf trees, $\mathrm{NT}=$ needleleaf trees, $\mathrm{C} 3=\mathrm{C} 3$ grasses and $\mathrm{C} 4=\mathrm{C} 4$ grasses.
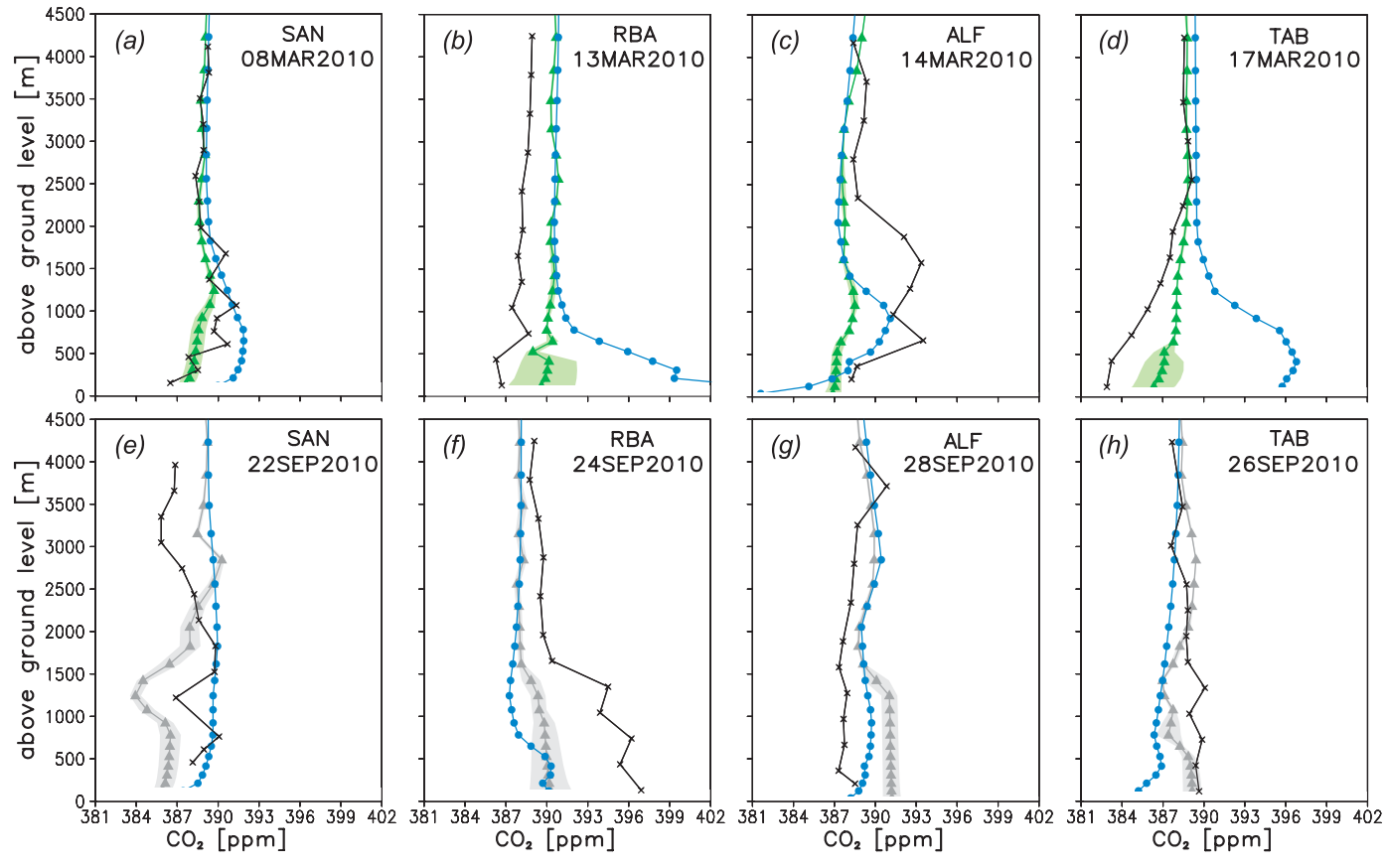

* Observ

$\rightarrow$ JULES_ad1_ae0

$\rightarrow$ JULES_ad0_ae1

$\rightarrow$ TM5

Fig. 9. Observed $\mathrm{CO}_{2}$ vertical profiles (black lines), simulated with CarbonTracker model (blue lines) and simulated with JULES-CCATTBRAMS (green and gray lines). The observations were collected at around 16:00 UTC, and the simulated profiles correspond to 15:00 UTC for CarbonTracker, because it has a temporal frequency of three hours, and a time average between 16:00 and 17:00 UTC for JULESCCATT-BRAMS (temporal frequency of one hour); green/gray shading represents the standard deviation of the time average. The title of each figure contains the respective locations and dates of the profiles, where $\mathrm{SAN}=\mathrm{Santarém}\left(54.95^{\circ} \mathrm{W}, 2.86^{\circ} \mathrm{S}\right)$, $\mathrm{RBA}=\mathrm{Rio} \mathrm{Branco}$ $\left(67.62^{\circ} \mathrm{W}, 9.38^{\circ} \mathrm{S}\right), \mathrm{ALF}=$ Alta Floresta $\left(56.75^{\circ} \mathrm{W}, 8.80^{\circ} \mathrm{S}\right)$ and $\mathrm{TAB}=$ Tabatinga $\left(70.06^{\circ} \mathrm{W}, 5.96^{\circ} \mathrm{S}\right)$.

as with the CarbonTracker modeling system. $\mathrm{CO}_{2}$ concentration from CarbonTracker was used as initial and boundary conditions for the JULES-CCATT-BRAMS simulations.

For the wet season, it is observed in this figure that, in general, the JULES-CCATT-BRAMS model obtained better results than CarbonTracker, mainly at the levels close to the surface. In higher levels, both models were able to simulate well the $\mathrm{CO}_{2}$ concentration, except for Rio Branco (RBA) on 13 March 2010, where the error was around 2 ppm, which corresponds to less than $1 \%$ of the observed concentration. The model errors in the lower levels, mainly within PBL, are higher and should be related to difficulties on simulating 


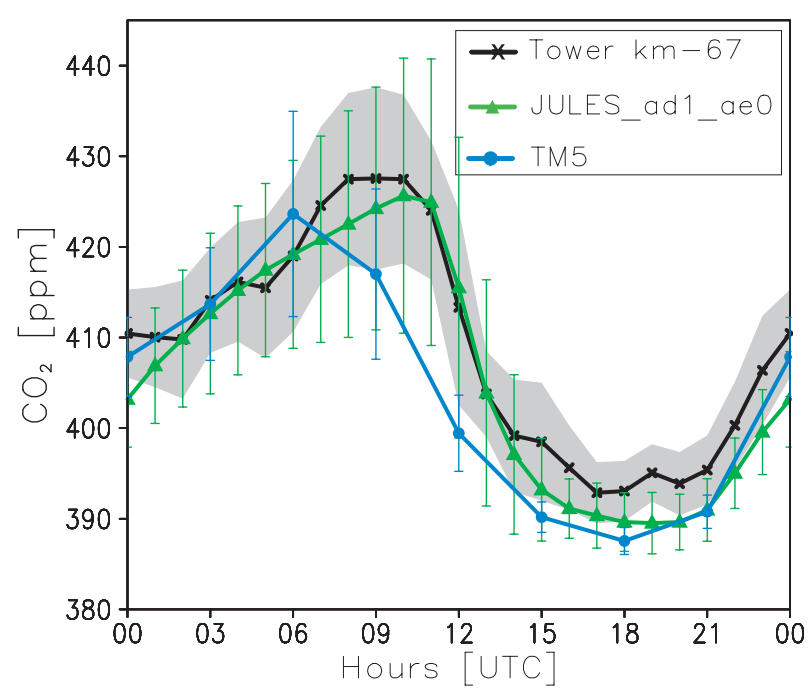

Fig. 10. Mean $\mathrm{CO}_{2}$ concentration diurnal cycle for the month of March 2010. The black line corresponds to the observed values at the $\mathrm{km} 67$ tower (Tapajós forest: $55.04^{\circ} \mathrm{W}, 2.85^{\circ} \mathrm{S}$ ) at an altitude of $57.9 \mathrm{~m}$; the green line corresponds to the JULES-CCATT-BRAMS experiment with monotonic advection; and the blue line refers to the CarbonTracker experiment, both bilinearly interpolated to the tower location and an altitude of $39.2 \mathrm{~m}$ (first model sigma level).

a number of atmospheric process (net surface radiation, subgrid-scale turbulent transport, sub-grid-scale transport by convection, for example) and carbon fluxes between surface and atmosphere. However, at higher levels JULES-CCATTBRAMS $\mathrm{CO}_{2}$ concentration follows very close to the CarbonTracker simulation, as one should expect.

The $\mathrm{CO}_{2}$ simulations for the dry season present little higher disagreements between model simulation and observation. One reason for that might be associated with the impact of $\mathrm{CO}_{2}$ emission by biomass burning in Amazon basin, which also has a high uncertainty at the flux estimation. In spite of the disagreement between the absolute values of $\mathrm{CO}_{2}$, the vertical structure of $\mathrm{CO}_{2}$ as simulated by JULES-CCATT-BRAMS resembles very well the observation, at least for the levels below $\sim 2500 \mathrm{~m}$. Above this height, the simulated profile is largely influenced by the CarbonTracker model data.

\subsection{2 $\mathrm{CO}_{2}$ diurnal cycle}

Figure 10 shows the daily evaluation of the mean $\mathrm{CO}_{2}$ concentration in the month of March 2010.

An increase is observed during the nighttime due to plant respiration, and a decrease is seen during the daytime due to photosynthetic processes. Thus, the maximum concentration normally occurs shortly after sunrise and the minimum before sunset. Also there is a build up of $\mathrm{CO}_{2}$ in the canopy in calm nights which flushes when the wind picks up in the morning. It is observed in this figure that JULES-CCATT-
BRAMS represents the diurnal $\mathrm{CO}_{2}$ cycle very well. CarbonTracker also had a good representation, although the figure shows its maximum concentration value shifted to earlier times compared with the observation, but one should notice that the temporal resolution of this model is $3 \mathrm{~h}$; thus, it is not possible to know if higher values exist between 06:00 UTC and 12:00 UTC. The underestimate in the diurnal cycle of approximately $3 \mathrm{ppm}$ in both models could be related to the fact that the model level is $17.8 \mathrm{~m}$ below the altitude at which the tower measurement was made. This difference is relatively small, but it is observed in Fig. 9 that the $\mathrm{CO}_{2}$ concentration can vary significantly in the lowest levels, due to the strong convective process during the daytime. Another possible reason for this underestimate in the daytime could be due to inaccuracies in the soil carbon map and its lower spatial resolution $\left(0.5^{\circ}\right)$. The JULES model is quite sensitive to this parameter; therefore, if the soil carbon prescribed to JULES is lower than the actual value at the tower location, the carbon flux from the soil might be underestimated.

\section{Conclusions}

This study aimed to include in CCATT-BRAMS model the surface model JULES which is today considered state-of-theart. It was shown that in addition to gains from the simulation of new processes, the new surface model also promoted major improvements of the main variables predicted by the CCATT-BRAMS model.

The simulations with the new JULES-CCATT-BRAMS system improved the regional modeling of surface temperature and dew point, which is believed to be associated with the better surface-atmosphere interaction provided by the JULES surface scheme. Surface atmospheric pressure was also improved. In the case of the surface wind speed, the comparison with observed data from surface stations showed that the original surface scheme (LEAF) provided better results. However, when compared with radiosounding data, similar errors in wind magnitude were observed for both surface schemes, JULES and LEAF, for all experiments.

The errors in temperature and pressure in the JULESCCATT-BRAMS simulations are lower than those of the ECMWF reanalysis. For the other variables, dew point and precipitation, the ECMWF reanalysis provided better results, but one should consider the fact that many of the data utilized as reference in the error calculation may have been used in the production of this reanalysis. Also, part of the errors presented in this work could originate in the NCEP analysis itself, which was used as initial and boundary conditions.

The JULES-CCATT-BRAMS model is now able to simulate the regional carbon cycle including anthropogenic (urban and biomass burning processes) and biogenic fluxes. The model simulation of surface $\mathrm{CO}_{2}$ at the $\mathrm{km} 67$ tower shows feasible agreement with observations. The simulations of vertical profiles over 4 sites of Amazon basin and for wet and 
dry seasons did not show very accurate agreement, mainly at lower levels. However, there are improvements in comparison with the CarbonTracker system, and the simulations performed in this work used the default settings of JULES surface scheme, which might not be optimized for the Amazon basin. The continuation of this work will take advantage of different techniques of flux estimation like inversion calculations.

Finally, the JULES soil/vegetation model coupled with the CCATT-BRAMS atmospheric chemistry model provided a significant gain in performance when compared to the original surface model (LEAF). Moreover, the new system represents an important step towards a better understanding of the interaction between the Amazonian ecosystem and regional atmospheric processes, due to the ability of JULES to simulate photosynthesis, respiration and dynamic vegetation, among other processes.

Instructions for compiling, executing, conducting a test case and running the JULES-CCATT-BRAMS model can be found in the supplementary material. The code package and initial conditions for the test case can be obtained from the BRAMS group at CPTEC/INPE (brams@ @ ctec.inpe.br). However, the JULES submodel can be used only for research purposes (non-commercial use), and signing the JULES license agreement is mandatory (see:https://jules.jchmr.org/ software-and-documentation).

\section{Supplementary material related to this article is

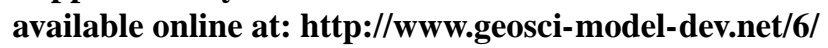 1243/2013/gmd-6-1243-2013-supplement.pdf.}

\begin{abstract}
Acknowledgements. The authors thank all the members of the Modeling of the Atmosphere and its Interfaces Group (GMAI), Chris Huntingford, Lucas Domingues, Alexandre Martinewski, Kenia Wiedemann and Marcos Longo. ECMWF ERA-Interim data used in this study were provided by the ECMWF data server: http://data-portal.ecmwf.int/data/d/interim_daily/levtype=pl/, and CarbonTracker $\mathrm{CO}_{2}$ data were provided by NOAA/ESRL (carbontracker.noaa.gov). This work was partially supported by the NERC consortium grant AMAZONICA Project (Natural Environment Research Council NERC/grant: NE/F005806/1) and the EU grant 7th framework GEOCARBON project (grant number agreement 283080). The authors thank these projects.
\end{abstract}

Edited by: J. C. Hargreaves

\section{References}

Andreae, M. O.: Biomass burning: its history, use and distribution and its impact on environmental quality and global climate, in: Global Biomass Burning, Atmospheric, Climatic and Biospheric Implications, edited by: Levine, J. S., MIT Press, Cambridge, Mass., 3-21, 1991.
Andreae, M. O., Rosenfeld, D., Artaxo, P., Costa, A. A., Frank, G. P., Longo, K. M., and Silva-Dias, M. A. F.: Smoking rain clouds over the Amazon, Science, 303, 1337-1342, doi:10.1126/science.1092779, 2004.

Artaxo, P., Martins, J. V., Yamasoe, M. A., Procópio, A. S., Pauliquevis, T. M., Andreae, M. O., Guyon, P., Gatti, L. V., and Leal, A. M. C.: Physical and chemical properties of aerosols in the wet and dry seasons in Rondônia, Amazonia, J. Geophys. Res., 107, 8081, doi:10.1029/2001JD000666, 2002.

Baker, T. R., Phillips, O. L., Malhi, Y., Almeida, S., Arroyo, L., Di Fiore, A., Erwin, T., Higuchi, N., Killeen, T. J., Laurance, S. G., Laurance, W. F., Lewis, S. L., Monteagudo, A., Neill, D. A., Núñez Vargas, P., Pitman, N. C. A., Silva, J. N. M., and Vásquez Martínez, R.: Increasing biomass in Amazonian forest plots, Philos. T. Roy. Soc. B, 359, 353-365, doi:10.1098/rstb.2003.1422, 2004.

Batjes, N. H.: Documentation to ISRIC-WISE Global Data Set of Derived Soil Properties on a 1/2 Deg by 1/2 Deg Grid (Version 1.0), Working Paper and Preprint 96/05, ISRIC, Wageningen, 1996.

Berge, E.: Coupling of wet scavenging of sulphur to clouds in a numerical weather prediction model, Tellus B, 45, 1-22, doi:10.1034/j.1600-0889.1993.00001.x, 1993.

Best, M. J., Pryor, M., Clark, D. B., Rooney, G. G., Essery, R .L. H., Ménard, C. B., Edwards, J. M., Hendry, M. A., Porson, A., Gedney, N., Mercado, L. M., Sitch, S., Blyth, E., Boucher, O., Cox, P. M., Grimmond, C. S. B., and Harding, R. J.: The Joint UK Land Environment Simulator (JULES), model description Part 1: Energy and water fluxes, Geosci. Model Dev., 4, 677-699, doi:10.5194/gmd-4-677-2011, 2011.

Bouttier, F. and Kelly, G.: Observing-system experiments in the ECMWF 4-D-Var data assimilation system, Q. J. Roy. Meteor. Soc., 127, 1469-1488, doi10.1002/qj.49712757419, 2001.

Clark, D. B., Mercado, L. M., Sitch, S., Jones, C. D., Gedney, N., Best, M. J., Pryor, M., Rooney, G. G., Essery, R. L. H., Blyth, E., Boucher, O., Harding, R. J., Huntingford, C., and Cox, P. M.: The Joint UK Land Environment Simulator (JULES), model description - Part 2: Carbon fluxes and vegetation dynamics, Geosci. Model Dev., 4, 701-722, doi:10.5194/gmd-4-701-2011, 2011.

Collatz, G. J., Ball, J. T., Grivet, C., and Berry, J. A.: Physiological and environmental regulation of stomatal conductance, photosynthesis and transpiration: a model that includes a laminar boundary layer, Agr. Forest Meteorol., 54, 107-136, doi:10.1016/0168-1923(91)90002-8, 1991.

Collatz, G. J., Ribas-Carbo, M., and Berry, J. A.: Coupled photosynthesis-stomatal conductance model for leaves of $\mathrm{C}_{4}$ plants, Funct. Plant Biol., 19, 519-538, 1992.

Dee, D. P., Uppala, S. M., Simmons, A. J., Berrisford, P. , Poli, P., Kobayashi, S., Andrae, U., Balmaseda, M. A., Balsamo, G., Bauer, P., Bechtold, P., Beljaars, A. C. M., van de Berg, L., Bidlot, J., Bormann, N., Delsol, C., Dragani, R., Fuentes, M., Geer, A. J., Haimberger, L., Healy, S. B., Hersbach, H. , Hólm, E. V., Isaksen, L., Kållberg, P., Köhler, M., Matricardi, M., McNally, A. P., Monge-Sanz, B. M., Morcrette, J.-J., Park, B.-K., Peubey, C., de Rosnay, P., Tavolato, C., Thépaut, J.-N., and Vitart, F.: The ERA-interim reanalysis: configuration and performance of the data assimilation system, Q. J. Roy. Meteor. Soc., 137, 553-597, doi:10.1002/qj.828, 2011. 
Essery, R. L. H., Best, M. J., Betts, R. A., Cox, P. M., and Taylor, C. M.: Explicit Representation of Subgrid Heterogeneity in a GCM Land Surface Scheme, J. Hydrometeorol., 4, 530-543, ISSN: 1525-755X, doi:10.1175/15257541(2003)004<0530:EROSHI> 2.0.CO;2, 2003.

Flatau, P. J., Tripoli, G. J., Verlinde, J., and Cotton, W. R.: The CSURAMS cloud microphysical Module: General Theory and Code Documentation, Technical Report 451, Dep. Atmos. Sci., Colorado State University, Fort Collins, CO, USA, 88 pp., 1989.

Freitas, S. R., Longo, K. M., Alonso, M. F., Pirre, M., Marecal, V., Grell, G., Stockler, R., Mello, R. F., and Sánchez Gácita, M.: PREP-CHEM-SRC - 1.0: a preprocessor of trace gas and aerosol emission fields for regional and global atmospheric chemistry models, Geosci. Model Dev., 4, 419-433, doi:10.5194/gmd-4419-2011, 2011.

Freitas, S. R., Longo, K. M., Chatfield, R., Latham, D., Silva Dias, M. A. F., Andreae, M. O., Prins, E., Santos, J. C., Gielow, R., and Carvalho Jr., J. A.: Including the sub-grid scale plume rise of vegetation fires in low resolution atmospheric transport models, Atmos. Chem. Phys., 7, 3385-3398, doi:10.5194/acp-7-3385-2007, 2007.

Freitas, S. R., Longo, K. M., Silva Dias, M. A. F., Chatfield, R., Silva Dias, P., Artaxo, P., Andreae, M. O., Grell, G., Rodrigues, L. F., Fazenda, A., and Panetta, J.: The Coupled Aerosol and Tracer Transport model to the Brazilian developments on the Regional Atmospheric Modeling System (CATT-BRAMS) Part 1: Model description and evaluation, Atmos. Chem. Phys., 9, 2843-2861, doi:10.5194/acp-9-2843-2009, 2009.

Freitas, S. R., Longo, K. M., Silva Dias, M. A. F., Silva Dias, P. L., Chatfield, R., Prins, E., Artaxo, P., Grell, G. A., and Recuero, F. S.: Monitoring the transport of biomass burning emissions in South America, Environ. Fluid Mech., 5, 135-167, doi:10.1007/s10652-005-0243-7, 2005.

Freitas, S. R., Rodrigues, L. F., Longo, K. M., and Panetta, J.: Impact of a monotonic advection scheme with low numerical diffusion on transport modeling of emissions from biomass burning, J. Adv. Model. Earth Syst., 4, M01001, doi:10.1029/2011MS000084, 2012.

Gatti, L. V., Miller, J. B., D’Amelio, M. T. S., Martinewski, A., Basso, L. S., Gloor, M. E., Wofsy, S., and Tans, P.: Vertical profiles of $\mathrm{CO}_{2}$ above eastern Amazonia suggest a net carbon flux to the atmosphere and balanced biosphere between 2000 and 2009, Tellus B, 62, 581-594, doi:10.1111/j.1600-0889.2010.00484.x, 2010.

Gedney, N., Cox, P. M., Betts, R. A., Boucher, O., Huntingford, C., and Stott, P. A.: Detection of a direct carbon dioxide effect in continental river runoff records, Nature, 439, 835-838, doi:10.1038/nature04504, 2006.

Gesch, D. B., Verdin, K. L., and Greenlee, S. K.: New land surface digital elevation model covers the Earth, EOS T. Am. Geophys. Un., 80, 69-70, 1999.

Gevaerd, R. and Freitas, S. R.: Estimativa operacional da umidade do solo para inicializaçãao de modelos de previssão numérica da atmosfera. Parte I: Descrição da metodologia e validação, Revista Brasileira de Meteorologia, 21, 1-15, 2006 (in Brazil).

Gregory, D. and Smith, R. N. B.: Canopy, Surface and Soil Hydrology, Unified Model Documentation Paper 25, Meteorological Office, London Rd, Bracknell, Berkshire, RG12 2SY, 1990.
Grell, G. A. and Dévényi, D.: A generalized approach to parameterizing convection combining ensemble and data assimilation techniques, Geophys. Res. Lett., 29, 38-1-38-4, doi:10.1029/2002GL015311, 2002.

Hughes, J. K., Valdes, P. J., and Betts, R.: Dynamics of a globalscale vegetation model, Ecol. Model., 198, 452-462, 2006.

Jacobs, C. M. J.: Direct impact of atmospheric $\mathrm{CO}_{2}$ enrichment on regional transpiration, Ph.D. thesis, Department of Meteorology, Wageningen Agricultural University, the Netherlands, 179 pp., 1994.

Kaufman, Y. J.: Remote sensing of direct and indirect aerosol forcing, in: Aerosol Forcing of Climate, edited by: Charlson, R. J. and Heintzenberg, J., John Wiley \& Sons, New York, 297-332, 1995.

Keeling, C. D.: Climate change and carbon dioxide: an introduction, P. Natl. Acad. Sci. USA, 94, 8273-8274, 1997.

Koren, I., Kaufman, Y. J., Remer, L. A., and Martins, J. V.: Measurement of the effect of Amazon smoke on inhibition of cloud formation, Science, 303, 1342-1345, doi:10.1126/science.1089424, 2004.

Krol, M., Houweling, S., Bregman, B., van den Broek, M., Segers, A., van Velthoven, P., Peters, W., Dentener, F., and Bergamaschi, P.: The two-way nested global chemistry-transport zoom model TM5: algorithm and applications, Atmos. Chem. Phys., 5, 417-432, doi:10.5194/acp-5-417-2005, 2005.

Longo, K. M., Freitas, S. R., Andreae, M. O., Setzer, A., Prins, E., and Artaxo, P.: The Coupled Aerosol and Tracer Transport model to the Brazilian developments on the Regional Atmospheric Modeling System (CATT-BRAMS) - Part 2: Model sensitivity to the biomass burning inventories, Atmos. Chem. Phys., 10, 57855795, doi:10.5194/acp-10-5785-2010, 2010.

Longo, K. M., Freitas, S. R., Pirre, M., Marécal, V., Rodrigues, L. F., Panetta, J., Alonso, M. F., Rosário, N. E., Moreira, D. S., Gácita, M. S., Fonseca, R., Stockler, R., Katsurayama, D. M., Fazenda, A., and Bela, M.: The chemistry CATT-BRAMS model (CCATT-BRAMS 4.5): a regional atmospheric model system for integrated air quality and weather forecasting and research, Geosci. Model Dev. Discuss., 6, 1173-1222, doi:10.5194/gmdd6-1173-2013, 2013.

Meesters, A. G. C. A., Tolk, L. F., and Dolman, A. J.: Mass conservation above slopes in the Regional Atmospheric Modelling System (RAMS), Environ. Fluid Mech., 8, 239-248, doi:10.1007/s10652-008-9072-9, 2008.

Mellor, G. L. and Yamada, T.: Development of a turbulence closure model for geophysical fluid problems, Rev. Geophys., 20, 851875, doi:10.1029/RG020i004p00851, 1982.

Mercado, L. M., Bellouin, N., Sitch, S., Boucher, O., Huntingford, C., Wild, M., and Cox, P. M.: Impact of changes in diffuse radiation on the global land carbon sink, Nature, 458, 10141017, doi:10.1038/nature07949, 2009.

Mercado, L. M., Huntingford, C., Gash, J. H. C., Cox, P. M., and Jogireddy, V.: Improving the representation of radiation interception and photosynthesis for climate model applications, Tellus B, 59, 553-565, doi:10.1111/j.1600-0889.2007.00256.x, 2007.

Olson, J. S.: Global Ecosystem Framework-Definitions, USGS EROS Data Center Internal Report, Sioux Falls, 37 pp., 1994.

Peters, W., Jacobson, A. R., Sweeney, C., Andrews, A. E., Conway, T. J., Masarie, K., Miller, J. B., Bruhwiler, L. M. P., Pétron, G., Hirsch, A. I., Worthy, D. E. J., van der Werf, G. R., 
Randerson, J. T., Wennberg, P. O., Krol, M. C., and Tans, P. P.: An atmospheric perspective on North American carbon dioxide exchange: CarbonTracker, P. Natl. Acad. Sci. USA, 104, 1892518930, doi:10.1073/pnas.0708986104, 2007.

Prins, E. M., Feltz, J. M., Menzel, W. P., and Ward, D. E.: An overview of GOES-8 diurnal fire and smoke results for SCAR-B and 1995 fire season in South America, J. Geophys. Res., 103, 31821-31835, doi:10.1029/98JD01720, 1998.

Procopio, A. S., Remer, L. A., Artaxo, P., Kaufman, Y. J., and Holben, B. N.: Modeled spectral optical properties for smoke aerosols in Amazonia, Geophys. Res. Lett., 30, 2265, doi:10.1029/2003GL018063, 2003.

Reid, J. S., Hobbs, P. V., Ferek, R. J., Blake, D. R., Martins, J. V., Dunlap, M. R., and Liousse, C.: Physical, chemical, and optical properties of regional hazes dominated by smoke in Brazil, J. Geophys. Res., 103, 32059-32080, doi:10.1029/98JD00458, 1998.

Reynolds, R. W., Rayner, N. A., Smith, T. M., Stokes, D. C., and Wang, W.: An improved in situ and satellite SST analysis for climate, J. Climate, 15, 1609-1625, doi:10.1175/15200442(2002)0152.0.CO;2, 2002.

Rosário, N. E., Longo, K. M., Freitas, S. R., Yamasoe, M. A., and Fonseca, R. M.: Modeling the South American regional smoke plume: aerosol optical depth variability and surface shortwave flux perturbation, Atmos. Chem. Phys., 13, 2923-2938, doi:10.5194/acp-13-2923-2013, 2013.

Rosenfeld, D.: TRMM observed first direct evidence of smoke from forest fires inhibiting rainfall, Geophys. Res. Lett., 26, 31053108, 1999.

Rossato, L, Alvalá, R. C. S., and Tomasella, J.: Distribuição geográfica da capacidade de armazenamento de água e das propriedades físicas do solo no Brasil, in: X Congresso Brasileiro de Meteorologia/VIII Congresso da FLISMET, Brasília, DF, Brazil, 1998 (in Portuguese).

Seinfeld, J. H. and Pandis, S. N.: Atmospheric Chemistry and Physics - from Air Pollution to Climate Change, 2nd Edn., ISSN: 978-0-471-72018-8, John Wiley \& Sons, New York, 1998

Sestini, M. F., Reimer, E. S., Valeriano, D. M., Alvalá, R. C. S., Mello, E. M. K., Chan, C. S., and Nobre, C. A.: Mapa de cobertura da terra da Amazônia legal para uso em modelos meteorológicos, Simpósio Brasileiro de Sensoriamento Remoto, 11, 2901-2906, 2003 (in Portuguese).

Sitch, S., Cox, P. M., Collins, W. J., and Huntingford, C.: Indirect radiative forcing of climate change through ozone effects on the land-carbon sink, Nature, 448, 791-794, doi:10.1038/nature06059, 2007.
Souza, E. P.: Estudo Teórico e Numérico da Relaçãao entre Convecção e Superfícies Heterogêneas na Região Amazônica, Ph.D. thesis, DCA/IAG, São Paulo University (USP), São Paulo, SP, Brazil, 1999 (in Portuguese).

Toon, O. B., Turco, R. P., Westphal, D., Malone, R., and Liu, M.: A multidimensional model for aerosols: description of computational analogs, J. Atmos. Sci., 45, 2123-2144, doi:10.1175/15200469(1988)0452.0.CO;2, 1988.

Tremback, C. J., Powell, J., Cotton, W. R., and Pielke, R. A.: The forward-in-time upstream advection scheme: extension to higher orders, Mon. Weather Rev., 115, 540-555, doi:10.1175/15200493(1987)1152.0.CO;2, 1987.

Tripoli, G. J. and Cotton, W. R.: The Colorado State University three-dimensional cloud mesoscale model, 1982: Part I: General theoretical framework and sensitivity experiments, Journal de Recherches Atmosphériques, 16, 185-220, 1982.

Walko, R., Band, L., Baron, J., Kittel, F., Lammers, R., Lee, T., Ojima, D., Pielke, R., Taylor, C., Tague, C., Tremback, C., and Vidale, P.: Coupled atmosphere-biophysics-hydrology models for environmental modeling, J. Appl. Meteorol., 39, 931-944, 2000.

Wesley, M. L.: Parameterization of surface resistance to gaseous dry deposition in regional numerical models, Atmos. Environ. 16, 1293-1304, 1989.

Xu, J.-Yu and Zhong, Q.: The Effect of Error Growth and Propagation on the Predictability of Quantitative Precipitation in a CloudResolving Model, Atmos. Ocean. Sci. Lett., 2, 79-84, 2009.

Yamasoe, M. A., von Randow, C., Manzi, A. O., Schafer, J. S., Eck, T. F., and Holben, B. N.: Effect of smoke and clouds on the transmissivity of photosynthetically active radiation inside the canopy, Atmos. Chem. Phys., 6, 1645-1656, doi:10.5194/acp-61645-2006, 2006.

Yang, Z. L., Dickinson, R. E., Henderson-Sellers, A., and Pitman, A. J.: Preliminary study of spin-up processes in land surface models with the first stage data of Project for Intercomparison of Land Surface Parameterization Schemes Phase 1(a), J. Geophys. Res., 100, 16553-16578, doi:10.1029/95JD01076, 1995.

Zhang, F., Odins, A. M., and Nielsen-Gammon, J. W.: : Mesoscale Predictability of an Extreme Warm-Season Precipitation Event, Weather Forecast., 21, 149-166, doi:10.1175/WAF909.1, 2006.

Zobler, L.: Global Soil Types, 1-Degree Grid (Zobler), data set, available at: http://www.daac.ornl.gov from Oak Ridge National Laboratory Distributed Active Archive Center, Oak Ridge, Tennessee, USA, last access: 7 December 2012, doi:10.3334/ORNLDAAC/418, 1999. 